\title{
Sciendo
}

\section{THE PHYSIOLOGICAL AND PRODUCTIVITY EFFECTS OF HEAT STRESS IN CATTLE - A REVIEW*}

\author{
Piotr Herbut ${ }^{1}$, Sabina Angrecka ${ }^{1 *}$, Dorota Godyń ${ }^{2}$, Gundula Hoffmann ${ }^{3}$ \\ ${ }^{1}$ Department of Rural Building, University of Agriculture, Al. Mickiewicza 24-28, 30-059 Kraków, \\ Poland \\ ${ }^{2}$ Department of Production Systems and Environment, National Research Institute \\ of Animal Production, 32-083 Balice n. Kraków, Poland \\ ${ }^{3}$ Department of Engineering for Livestock Management, Leibniz Institute for Agricultural Engineering \\ and Bioeconomy, Max-Eyth-Allee 100, 14469 Potsdam, Germany \\ •Corresponding author: s.angrecka@ur.krakow
}

\begin{abstract}
A trend of global warming has been observed over the last few years and it has often been discussed whether there is an effect on livestock. Numerous studies have been published about heat stress in cattle and its influence on the physiology and productivity of animals. Preventing the negative effects of heat stress on cattle is essential to ensure animal welfare, health and productivity. Monitoring and analysis of physiological parameters lead to a better understanding of the adaptation processes. This can help to determine the risk of climate change and its effects on performance characteristics, e.g. milk yield and reproduction. This, in turn, makes it possible to develop effective measures to mitigate the impact of heat load on animals. The aim of this article is to provide an overview of the current literature. Studies especially about the physiological and productive changes due to heat stress in cattle have been summarised in this review. The direction of future research into the aspect of heat stress in cattle is also indicated.
\end{abstract}

Key words: cattle, heat stress, welfare, physiology, performance

The optimal level of milk production during heat waves is a problem which is likely to become very significant for cattle breeders throughout the world. Estimated by St-Pierre et al. (2003), milk yield loss in the United States of America alone exceeded USD 900 million/year stemming from decreased milk production, compromised reproduction and increased culling causes (Collier et al., 2006). All of these were due to increased ambient temperature. In 2014 in the USA, losses estimated using present-day prices were USD 670 million/year, and this will probably rise to

\footnotetext{
*The research was financed by the Ministry of Science and Higher Education of the Republic of Poland by statutory activity.
} 
USD 2.2 billion/year by the end of the century (Mauger et al., 2015). According to data of the Food and Agriculture Organization of the United Nations, the USA is one of the largest cow's milk producers in the world (in 2014, accounting for $14.2 \%$ of world production), next to India, China, Germany and Brazil. Geographic variation is one of the factors affecting the decline in milk production (Mauger et al., 2015). Taking into account the locations in the world of the largest milk producers and the deteriorating heat conditions for cows, the forecasting of heat stress is essential for maintaining global milk production at an appropriate level.

Stress determines the magnitude of forces external to the body's system, causing a displacement of this system from the resting (ground) state (Lee, 1965). It is widely known that animal body functions are most efficient within the thermo-neutral zone, while both the upper and lower critical may contribute to stress.

The degree of the stimulation of the body system determines the intensity of the stress response as well as the consequences which they bring to the organism. The aforementioned response of the dairy cattle body may vary depending on the genotype of individual breeds (Adamczyk et al., 2013; Yazgan et al., 2013). Apart from many negative consequences in terms of well-being and significant losses in milk production (Broucek et al., 2009), heat stress causes numerous physiological and behavioural disturbances (West et al., 2003; Gaworski and Rocha, 2016; Pilatti et al., 2018). Currently, increasingly more is known about the other effects of high ambient temperatures, such as an induction of defects in the intestinal barrier function found in heat-stressed animals, which may lead to increased permeability for bacteria (Baumgard et al., 2015). Moreover, the development of molecular biology techniques has made it possible to also determine the effect of high ambient temperature on a cell structure and its functions (Altan et al., 2003).

When the optimal conditions are exceeded, the cow's body attempts to adapt to the new environmental situation. At higher air temperatures, however, the adaptive mechanisms of cows fail to remove the excess heat generated. The animal can radiate body heat based on the principles of convection, conduction, radiation and evaporation mainly through increased respiration rate, panting and sweating. Behavioural coping strategies include increased standing time, shade seeking and decreased activity and movement (Schutz et al., 2009). It is essential to remove excess body heat to prevent the animal from entering into a stage of hyperthermia. Therefore, the maintenance of the correct temperature for the cows is a crucial condition for their high productivity and general health.

The occurrence of heat stress may be restricted to one or several days, but it may also extend over a longer period. Other factors influencing the risk of the occurrence of heat stress in cows include the breed of the cow, its age and lactation phase and milk production level. Due to the positive relationship between milk yield and heat production, higher yielding cows are more challenged by heat stress than lower yielding animals. However, the extent to which milk production is affected also depends on traits and parities. Multiparous cows are more susceptible to heat stress than primiparous cows (Bernabucci et al., 2014).

The use of technical solutions to control the animal's microclimate can contribute to alleviating the effects of heat stress in cows (Kadzere et al., 2002; West, 2003; 
Lendelova et al., 2012; Pilatti and Vieira, 2017). In applying appropriate solutions, there are various cooling options for dairy cows. Other methods include misting and air-mixing devices, and water droplets from low-pressure sprinkler systems. Increasingly often various methods of increasing shade coverage are mentioned in the literature, including tree coverage, roofs, extensions of eaves, and the installation of sunlight-reducing mesh. This creates more hospitable microclimates for cows due to the reduction in solar radiation exposure and decline in ambient temperature (Schutz et al., 2009; Herbut et al., 2013; Van Laer et al., 2014; Angrecka and Herbut, 2016).

The aim of this paper is to review and systematize the current state of knowledge on the topic of the physiological and related productivity changes caused by thermal stress in cattle.

\section{Environmental parameters as risk factor}

Cows are well able to adapt to changeable temperature and humidity conditions throughout the year (Kadzere et al., 2002). This can be confirmed by a relatively wide range of neutral temperatures established for dairy cattle. Fluctuations of temperature within a range of $-0.5-20.0^{\circ} \mathrm{C}$ and $60-80 \%$ relative humidity (West, 2003) is generally accepted as a thermo-neutral value that does not significantly influence physiological changes among cows. As Berman et al. (1985) has claimed, the upper limit of air temperature at which the cow's body core temperature may be maintained is $25.0-26.0^{\circ} \mathrm{C}$.

The air temperature and relative humidity are considered as the most important factors which determine the exchange of heat between an animal's body and its surroundings. However, other relevant microclimate elements - such as air movement and sunlight - also play a significant role in induction of heat stress response in animals (West, 2003; Da Silva et al., 2010). Changes in air velocity influence the convection cooling of cattle (Davis and Mader, 2003). The effective air velocity recommended for dairy cattle in the United States during heat stress is from 1.8 to $2.8 \mathrm{~m} \cdot \mathrm{s}^{-1}$ (Bailey et al., 2016). Berman (2005) stated that air velocity was reduced by cows moving in the barn, so that its measurements do not always reflect real values. This is consistent with the research of Herbut (2013) and Hempel (2018), who have pointed out the need to perform measurements throughout the whole area housing the cows, not just at individual measurement points. It is also worth noting that, during the heat period, the use of air velocities above $1.0 \mathrm{~m} \cdot \mathrm{s}^{-1}$ with increased humidity (e.g. through sprinklers) effectively cools cows (Kadzere et al., 2002).

Solar radiation is one of the leading environmental factors that affect livestock (Schutz et al., 2009). Global radiation includes both direct radiation, arriving directly from the sun, and the diffuse radiation received from the blue sky and/or reflected by the clouds (Da Silva et al., 2010). The impact of radiation, whether direct, scattered, or reflected, may be the main determinant of the environmental conditions in which the cows are kept. Primarily, it applies to pastures, but also the barns (Schutz et al., 2008; Tucker et al., 2008). Studies conducted in free stall barns showed a significant variation in microclimate conditions. These variations result from the higher air and litter surface temperature experienced during the day in cubicles adjacent to walls 
which are exposed to solar radiation, as compared to cubicles in shade (Angrecka and Herbut, 2016).

Many environmental indices have been proposed which are based on the measurement of meteorological factors, such as Temperature Humidity Index (THI), Black Globe-Humidity Index (BGHI) and Environmental Stress Index (ESI). It has been proven that the heat stress situation is worse when the high air temperature is associated with high relative humidity in the animals' environment (Hill and Wall, 2015; Herbut et al., 2018 b). Over the years, two main methods of assessing environmental risk factors and the animals' reaction to changing environmental conditions have been developed. The first of these are a variety of different temperaturehumidity indices expressed in absolute units that define the thermal comfort of the cows with the changing parameters of their environment. The second are algorithms expressed in ${ }^{\circ} \mathrm{C}$, which are intended to define the temperature as experienced by the animal. The indices have undergone numerous modifications and feature a variety of different ranges of values defining the extent of heat stress among dairy cows. The threshold values indicating occurrence of heat stress among cows and individual levels of thermal stress have been developed for these indices (Herbut et al., 2018 b; Wang et al., 2018).

\section{Physiological changes}

The body core temperature of cows in thermo-neutral conditions is maintained by the thermoregulation system of the animal's body with a range of about $1{ }^{\circ} \mathrm{C}$ (between 38 to $39.2^{\circ} \mathrm{C}$ ) (Ammer et al., 2016). Under these ambient conditions, the exchange of animal heat within a body (across cellular and vascular membranes), and between a body and its environment, are kept in balance; however, it is always a dynamic equilibrium (Taylor et al., 2014).

During periods of excess heat in the animal environment, homeostatic mechanisms of the body are activated to re-establish the thermal status of the internal environment or to regulate it within acceptable physiological limits (Werner et al., 2008). The mechanisms to eliminate excess heat undergo regulation where the centre of it is located in the hypothalamus. It receives information on the fluctuations of temperatures in both surface and deep tissues of the body, as these receptors are components of the thermal feedback loops (Werner et al., 2008; Taylor et al., 2014). Heat stress conditions induce at first an acute response which is initially driven by receptors of the skin. The consequence is the activation of the central nervous system and, next, the endocrine system and peripheral components of the autonomic system (Collier et al., 2012). Sweating and panting have been considered as two of the primary autonomic responses in heat-stressed animals. Collier et al. (2012) reported that an animal body enters the acute phase of stress response when skin temperature increases during exposure to heat, and reaches the value of $35^{\circ} \mathrm{C}$, and the respiratory rate is $60-70$ breaths/min. Lemerle and Goddard (1986) showed that the respiration rate begins to gradually increase as early as $\mathrm{THI}>73$, with a rapid increase noted at THI $>80$. As was proven, the value of this physiological parameter depends on the amount of shade (which means less radiant heat load and a cooler ambient temperature) and cooling in the area where the cows are kept, on their age, and on whether 
they spend time lying or standing. Among mature standing cows, the reaction to heat stress is an increase in respiration rate to approximately 80 breaths/min (Stevens, 1981). Moreover, Collier et al. (2006) showed that cows kept in shaded areas had respiration rates of 54 breaths/min, while cows in shadeless areas took 82 breaths $/ \mathrm{min}$. As Eigenberg et al. (2005) have stated, in the case of cows kept in an unshaded area, the respiration rate during the course of the day was more than about 16 breaths $/ \mathrm{min}$ higher than among cows kept in shaded areas. Cows kept in free stall barns (loose housing system) with a cooling system show a decrease in the number of breaths per minute from 95 to 57 (West, 2003). Based on studies conducted in the afternoon hours, Chaiyabutr et al. (2008) found that cows kept in cooled areas took 64 breaths/ min, while cows in uncooled areas took 86 breaths/min (Figure 1).
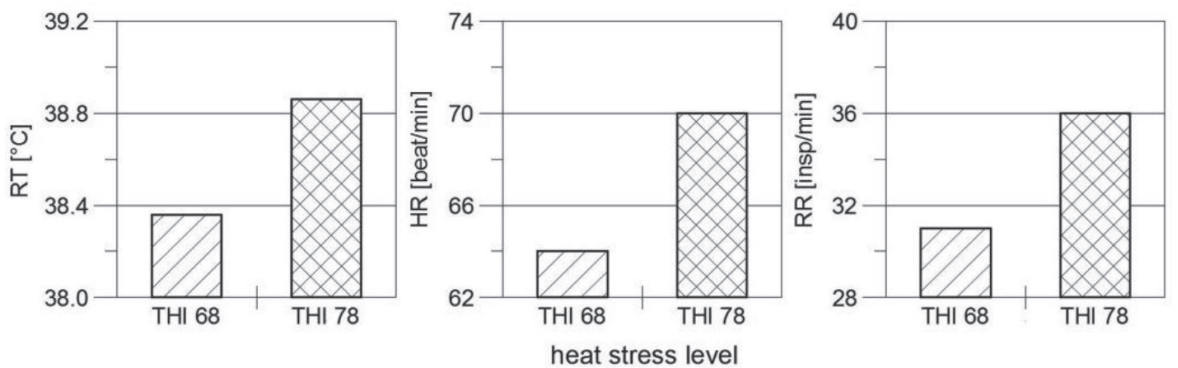

Figure 1. Heat stress effects on rectal temperature (RT), heart rates (HR) and respiration rate (RR) (Bouraoui et al., 2002)

During a body's exposure to heat the cardiac output increases. Taking into consideration the fact that stroke volume is maintained or only slightly increased, it needs to be stated that a rise in heart rate is the primary driving force behind this process (Johnson and Proppe, 1996). Heart rate control and regulation during exposure of a body to heat may be linked with the direct effects of temperature on the sinoatrial node and sympathetic and parasympathetic effects on the heart (Wilson and Crandall, 2011). Kovács et al. (2018) have shown that Holstein bull calves exposed to extreme heat load conditions without shade had a higher heart rate than calves kept in shaded pens. Bun et al. (2018) confirmed this finding in shaded and non-shaded dairy cows. Dalcin et al. (2016) found that at a BGHI value of 72 the heart rate starts to increase linearly in dairy cattle.

When the thermoregulation mechanisms to dissipate the external heat fail, the body core temperature rises and, according to Risco and Benzaquen (2011), values $>39.4^{\circ} \mathrm{C}$ represent a state of hyperthermia. Nowadays, both the changes of skin surface temperature and body core temperature may be easy to monitor using noninvasive methods such as thermography (Godyń et al., 2013; Hoffmann et al., 2013; Unruh et al., 2017) or small wireless sensors (e.g. rumen boluses) (Lees et al., 2018). Core body temperature in cattle may be measured in different body sites such as the rumen, ear canal and vagina, however the most common method of internal temperature assessment is the measuring of rectal temperature. Lemerle and Goddard (1986) 
discovered that rectal temperature begins to increase at values of THI $>80$. Collier et al. (2006), taking into consideration these measurements, found that cows kept in shaded areas had a rectal temperature lower by $0.5^{\circ} \mathrm{C}\left(38.9\right.$ to $\left.39.4^{\circ} \mathrm{C}\right)$ than those of cows exposed to full sunlight without access to shade.

Another important aspect of heat stress response of the animal body is increased expression of heat shock proteins (HSP) (Min et al., 2015). It is worth adding that HSP synthesis is caused by both extracellular agents (stressors) as well as harmful metabolites occurring inside the cell. Among different families of these proteins, HSP70 and HSP90 are especially considered to be related with the development of temperature tolerance (Hue et al., 2013). Briefly, the main role of these molecules is to ensure the folding, unfolding and refolding of nascent or stress-denatured proteins (Morimoto et al., 1990). Min et al. (2015), based on their findings of higher serum HSP70 and heat shock transcription factor (HSF) in cattle, concluded that these may be reliable indicators in alerting to heat stress situations.

Increased level of HSP in acute stress situations may also affect the activation of the innate immune system (Collier et al., 2012). Moreover, long term heat stress situations may reduce the effectiveness of the immune response to bacterial and viral infections. This may lead to the occurrence of lameness, mastitis and the formation of ketosis (Kadzere et al., 2002). Nowadays it is a well-known fact that heat stress affects a decrease of intestinal barrier function (Baumgard et al., 2015). Describing this briefly, it may be stated that hypoxia in the intestinal tissues (caused by redirecting blood to peripheral parts of the body) is associated with another adverse phenomenon of oxidative stress. This process impairs the cells morphology as well as their function and consequently may lead to an increase of gram negative bacteria or their wall components and to endotoxin (lipopolysaccharides, LPS) penetration from the gut into the portal and systemic blood (Pearce et al., 2013).

It is also widely known that heat stress causes disturbances in reproduction. It has been suggested that it is partly the result of reduced dry matter intake (DMI) (Westwood et al., 2002). However, Baumgard et al. (2015) pointed out that some of these problems are related to the aforementioned endotoxemia. Bacterial infections (marked with LPS) were shown to be linked with a reduction in estradiol production or a low number of primordial follicles (Battaglia et al., 2000; Bromfield and Sheldon, 2013). It was also proven that LPS reduced the expression of progesterone receptors in pregnant mice (Agrawal et al., 2013). Moreover, studies show that it may cause a delay of ovulation or may influence corpus luteum regression (Lavon et al., 2011). The lower level of $17 \beta$-estradiol may be a reason of disturbances in demonstration of the signs of oestrus in female cattle (Battaglia et al., 2000).

Homeorhetic mechanisms (long-term adaptation) induce a shift in energy metabolism to decrease metabolic heat production (Baumgard and Rhoads, 2012). Reduced feed intake entails negative energy balance, but instead of mobilization of fat stores, the animal body uses primarily glucose and muscle-derived proteins as fuel (Rhoads et al., 2013). The biological oxidation of sugars and amino acids produce less heat than the oxidation of fatty acids (Rhoads et al., 2013). This is why, during heat stress, blood insulin concentrations increase and glucose concentrations decrease (Rhoads et al., 2009). Hyperinsulinemia seems to be one of the major phenomena linked with 
metabolic adaptation to heat stress (Wheelock et al., 2010). However, this state leads to a nutrient trafficking problem which affects milk yield (Baumgard et al., 2015). Lactose is synthesised from blood glucose; hence, reduced blood glucose concentration is a limiting factor in lactose synthesis and consequently milk production. The pronounced trend in carbohydrate and glucose metabolism is a major factor to be considered in herd health monitoring and feeding strategies (Baumgard et al., 2015).

Numerous studies performed on farm animals show that exposure to high ambient temperatures is also related with an occurrence of oxidative stress (Bernabucci et al., 2002; Turk et al., 2015). Excessive amounts of reactive oxygen species (ROS) have an adverse effect on the structure and functioning of the cells (Altan et al., 2003). Unpaired electrons easily take part in various types of reactions within a cell causing, among others, protein damage, oxidation of nucleic acid components or lipid peroxidation (Deaton and Marlin, 2003). The levels of lipid peroxidation products, such as malondialdehyde (MDA) and thiobarbituric acid-reactive species (TBARS), are important oxidative stress markers (Dotan et al., 2004). In addition, the activity of some enzymes, such as catalase (CAT), glutathione peroxidase (GPx) and superoxide dismutase (SOD), plays a key role in the neutralisation of free radicals (Akbarian et al., 2016). Determination of some vitamin levels is also a very important parameter in evaluating oxidative stress. Harmon et al. (1997) are among the first authors to notice low levels of vitamin $\mathrm{E}$ in the plasma of cows exposed to high air temperatures. Padilla et al. (2006) found a reduction of vitamin C in the plasma of heat-stressed cows.

Currently, epigenetic studies are increasing in popularity with regard to evaluating the effect of heat stress in cattle (Johnson et al., 2013; Boddicker et al., 2014). It was shown that environmental factors (including heat stress) affect both prenatal and postnatal life (Boddicker et al., 2014). Heat stress, among other factors, may cause DNA modifications (mostly via methylation of DNA) that are capable of affecting gene expression and the cellular phenotype. These modifications are not a result of differences in DNA base pair sequence (Baumgard et al., 2012). These processes may lead to an improvement of the genome plasticity and thus to creating better responses to specific environmental conditions. Therefore, the DNA modifications may lead also to better postnatal protection against the negative effects of high ambient temperatures (Baumgard et al., 2012).

\section{Productive changes}

Numerous scientific publications show a link between heat stress occurrence and reduced DMI (Figure 2), as it is an immediate coping (Kadzere et al., 2002; West, 2003; Rhoads et al., 2009). Decreasing animal productivity during heat stress is only partly explained by reduced DMI. Baumgard et al. (2011) claim that the lower consumption in heat-stressed cattle explains only $35-50 \%$ of milk yield decrease. According to Slimen et al. (2016), heat stress causes the reorganisation of the use of body resources such as fat, protein and energy. The post-absorptive metabolism is altered which may occur regardless of the declines in feed intake (Slimen et al., 2016). However, Noordhuizen and Bonnefoy (2015) found a drop in milk production of as much as $600-900 \mathrm{~kg}$ of milk per cow per lactation, and a drop in feed intake of 
$0.85 \mathrm{~kg}$ DMI per cow less for each rise in $1{ }^{\circ} \mathrm{C}$ ambient air temperature (West, 2003). According to Kadzere et al. (2002), DMI among cows may drop by as much as $40 \%$ when the ambient temperature exceeds $30^{\circ} \mathrm{C}$, leading to a deterioration in energy balance. As estimated by Bouraoui et al. (2002), a reduction in DMI of 9.6\% was related to an increase of THI value from 68 to 78. In a study of West (2003), feed intake began to decrease one day after heat stress occurred. In addition, West (2003) observed a decrease in milking performance after 2 days, but the study was conducted in the humid subtropical climate of the southern USA. The research of Herbut et al. (2018 a), conducted in free stall barns, also revealed a 2- to 4-day delay in milking performance decline. The investigations have demonstrated that a decrease in cow milking performance depends also on the severity of the heat wave and the length of heat during the preceding periods. July and August, with a high number of hot and very hot days, caused that, in September, the cows responded faster to a worsening of thermal conditions (Herbut et al., 2018 a).

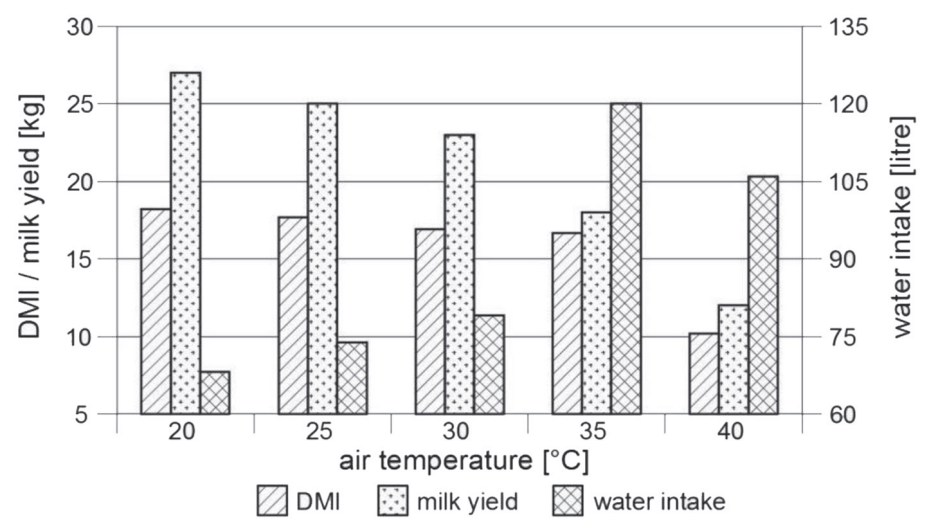

Figure 2. Relative changes in dry matter (DMI), milk yield and water intake with increasing environmental temperature (National Research Council, 1981)

Water intake is also very important for dairy cattle (Figure 2). For cows producing daily $41.5 \mathrm{~kg}$ of milk in thermo-neutral conditions, the water intake is about $135 \mathrm{~kg} /$ day (Kadzere et al., 2002). Variations in water intake are closely related to DMI and milk yield, ambient temperature and relative humidity (Cardot et al., 2008). Water for dairy cattle must be provided in the right quantity and temperature, because a drop in water in the body of cows by $10 \%$ may adversely affect milk production (González Pereyra et al., 2010).

Due to the positive relationship between milk yield and heat production, higher yielding cows are more challenged by heat stress than lower yielding animals. In the studies conducted by Purwanto et al. (1990), metabolic heat production among Holstein-Friesian cows with a daily yield of 18.5 and $31.6 \mathrm{~kg}$ was determined to be responsible for the generation of 27.3 and $48.5 \%$ more heat, respectively, than in the case of dry cows. This is related to the cows' high productivity, as well as to the susceptibility and sensitivity to heat stress, but it also depends on the breed of cow 
(Hammami et al., 2013; Bellagi et. al., 2017). Smith et al. (2013) state that, when THI $>72$, Holstein-Friesian cows experience a reduction in milk production from 35.6 to $34.2 \mathrm{~kg} / \mathrm{d}(-3.9 \%)$, but other indices also show a relationship with milk yield decrease (Figure 3). This drop in milk productivity has also been pointed out in a study by Bernabucci et al. (2002), who noted that summertime milk productivity was lower by $10 \%$ than springtime productivity $(26.7$ and $29.5 \mathrm{~kg} / \mathrm{d}$, respectively). However, the extent to which milk production is affected is also influenced by parities. Multiparous cows are more susceptible to heat stress, and the decrease in milk yield can reach as much as $1 \mathrm{~kg} / \mathrm{d}$ (Bernabucci et al., 2014).

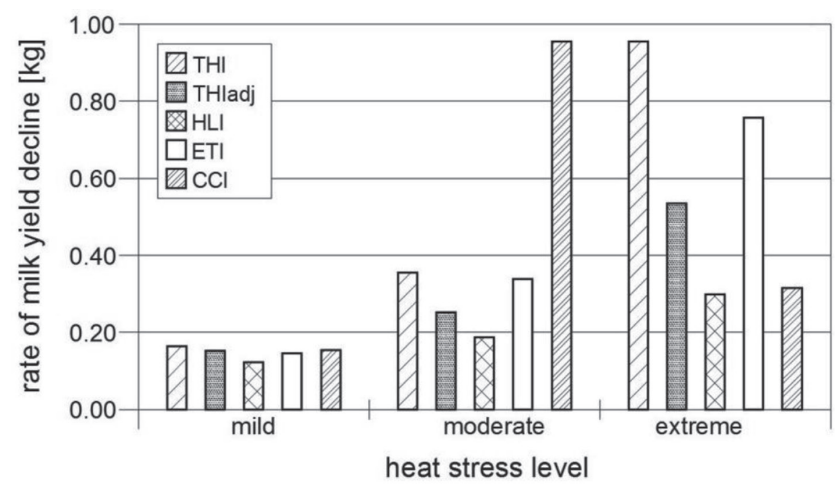

Figure 3. Rate of milk yield decline with different heat stress indices (Hammami et al., 2013)

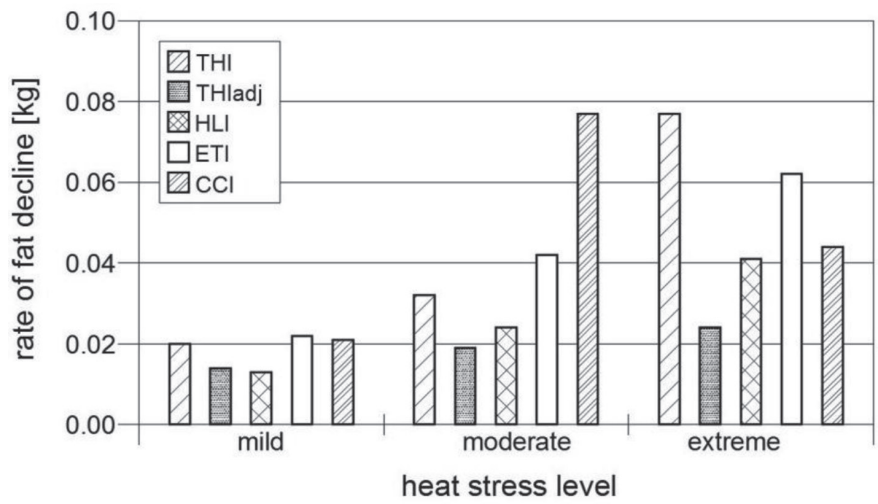

Figure 4. Rate of milk fat decline with different heat stress indices (Hammami et al., 2013)

Results obtained from the research conducted by a variety of authors (Bouraoui et al., 2002; Hammami et al., 2013) also indicate a direct link between heat stress and the deterioration of milk quality (Figures 4, 5). Deteriorating hygrothermal conditions cause an increase of the somatic cell count and a decrease of fat and protein in milk (Hammami et al., 2013; Lambertz et al., 2014). Somatic cell growth occurs with an increase in THI. The results confirming these phenomena were described by Van Laer et al. (2014) for southern Europe with a THI > 72 and Kadzere et al. (2002) where, in the air temperature of $30^{\circ} \mathrm{C}$, the fat and protein in milk content is less than 
in $15^{\circ} \mathrm{C}$. In turn, Pragna et al. (2017) in their review article compared the different cow breeds' reactions (e.g. Jersey, Holstein-Friesian, Zebu cattle (Bos indicus)) to heat stress. The occurrence of heat stress decreased milk yield and caused a deterioration in milk composition (reduction of milk fat and protein) for the Jersey and Holstein-Friesian cows. The Zebu cattle did not show any significant differences in milk yield and composition during heat stress.

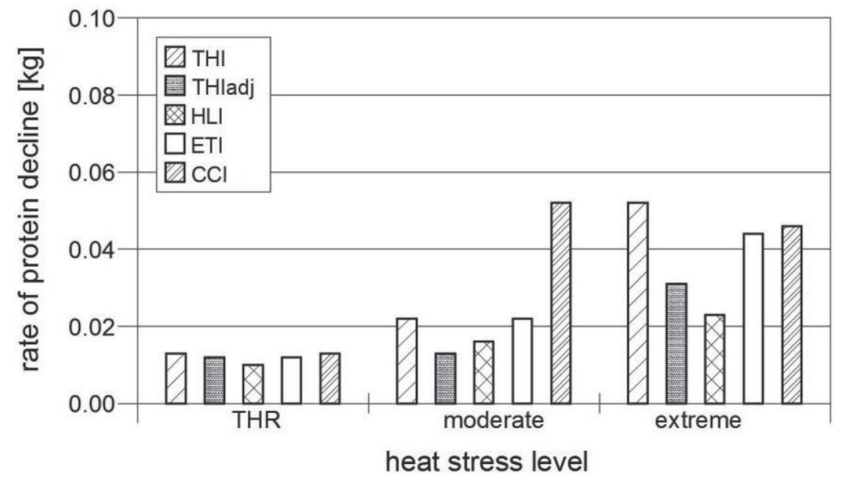

Figure 5. Rate of milk protein decline with different heat stress indices (Hammami et al., 2013)

\section{Conclusions}

The exposure of cattle, especially high milk producing cows, to heat stress conditions results in significant changes in the physiological and biochemical parameters in their organism. Early forecasting of heat stress risks makes it possible to limit its negative impact on the welfare and productivity of cattle. Therefore, the animal's comfort should be assessed based on the reliable environmental indices and the animal's response studies. It is important to evaluate the abilities of the animal body to cope with heat-stress related difficulties. This can be achieved in the future by using different sources of information based on the routinely and historically collected herd data and information about the environmental conditions.

In order to eliminate, or at least mitigate, the negative effects of heat stress, there is reason to endeavour to improve the genetic composition of dairy cows; therefore, there is a need to search for information concerning genetic differences in cattle tolerance to heat stress. One such method is modelling the performance of cows as a function of continuous THI, which leads to the identification of highly productive dairy cows with low sensitivity to THI variations.

\section{References}

A damczyk K., Pokorska J., Makulska J., Earley B., Mazurek M. (2013). Genetic analysis and evaluation of behavioural traits in cattle. Livestock Sci., 154: 1-12.

A grawal V., Ja is wa 1 M.K., Ja is wal Y.K. (2013). Lipopolysaccharide-induced modulation in the expression of progesterone receptor and estradiol receptor leads to early pregnancy loss in mouse. Zygote, 21: 337-344.

Akbarian A., Michiels J., Degroote J., Majdeddin M., Golian A., De Smet S. 
(2016). Association between heat stress and oxidative stress in poultry; mitochondrial dysfunction and dietary interventions with phytochemicals. J. Anim. Sci. Biotechnol., 7: 37.

A 1 t an O., Pabuccuoglu A., A 1 ton A., Konyalioglu S., B ay raktar H. (2003). Effect of heat stress on oxidative stress, lipid peroxidation and some stress parameters in broilers. Br. Poultry Sci., 4: 545-550.

A mmer S., Lambertz C., Gauly M. (2016). Comparison of different measuring methods for body temperature in lactating cows under different climatic conditions. J. Dairy. Res., 83: $165-172$.

A n g r e c k a S., Herbut P. (2016). Impact of barn orientation on insolation and temperature of stalls surface. Ann. Anim. Sci., 16: 887-896.

B a il ey T., Sheets J., M c Clary D., S mith S., B ridges A. (2016). Heat Abatement. Elanco.

B a t t a g li a D.F., Kra s a H.B., P a d m a n a b han V., Vigu i e C., K a r s c h F.J. (2000). Endocrine alterations that underlie endotoxin-induced disruption of the follicular phase in ewes. Biol. Reprod., 62: 45-53.

B a u m g a r d L.H., R h o a d s RP. (2012). Ruminant production and metabolic responses to heat stress. J. Anim. Sci., 90: 1855-1865.

B a u m g a r d L.H., W h e e 1 o c k J.B., S a n d e r s S.R., M o or e C.E., G r e en H.B., Wa 1 d r o n M.R., R h o a d s R.P. (2011). Post absorptive carbohydrate adaptations to heat stress and monensin supplementation in lactating Holstein cows. J. Dairy Sci., 94: 5620-5633.

B a u m gard L.H., Rhoads R.P., Rhoads M., Gabler N., Ross J., Keating A., B od d i c k e r R., L e n k a S., S e j i a n V. (2012). Impact of climate change on livestock production. In: Environmental stress and amelioration in livestock production, Sejian V., Nagvi S., Ezeji T., Lakritz J., Lal R. (eds). New York, NY: Springer Publ., pp. 413-468.

B a u m gard L.H., Ke at ing A., R os s J.W., Rhoads R.P. (2015). Effects of heat stress on the immune system, metabolism and nutrient partitioning: implications on reproductive success. Rev. Bras. Reprod. Anim., 39: 173-183.

Bellagi R., Martin B., Chassaing C., Najar T., Pomies D. (2017). Evaluation of heat stress on Tarentaise and Holstein cow performance in the Mediterranean climate. Int. J. Biometeorol., 61: 1371-1379.

B erman A. (2005). Estimates of heat stress relief needs for Holstein dairy cows. J. Anim. Sci., 83: 1377-1384.

B erman A., Folman Y., Kaim M., Mamen M., Herz Z., Wolfenson D., Arieli A., Graber Y. (1985). Upper critical temperatures and forced ventilation effects for high yielding dairy cows in a sub-tropical climate. J. Dairy Sci., 68: 1488-1495.

B ernabuc ci U., La cetera N., R on chi B., N ardone A. (2002). Effects of the hot season on milk protein fractions in Holstein cows. Anim. Res., 51: 25-33.

Bernabucci U., Biffani S., Buggiotti L., Vitali A., Lacetera N., Nardone A. (2014). The effects of heat stress in Italian Holstein dairy cattle. J. Dairy. Sci., 97: 471-486.

B oddicker R.L., S e ib e rt J.T., J ohns on J.S., P e a r c e S.C., S e ls by J.T., Gabler N.K., Lucy M.C., S afranski T.J., Rhoads R.P., B a umgard L.H., Ros s J.W. (2014). Gestational heat stress alters postnatal offspring body composition indices and metabolic parameters in pigs. PloS One, 9: e110859.

B oura ou i R., Lahmar M., Majd oub A., Dje mali M., B e lye a R. (2002). The relationship of temperature-humidity index with milk production of dairy cows in a Mediterranean climate. Anim. Res., 51: 479-491.

B ro m fi e ld J.J., S h eld on I.M. (2013). Lipopolysaccharide reduces the primordial follicle pool in the bovine ovarian cortex ex vivo and in the murine ovary in vivo. Biol. Reprod., 88: 1-9.

Broucek J., Novak P., Vokralova J., S o ch M., K is a c P., Uhrincat M. (2009). Effect of high temperature on milk production of cows from free-stall housing with natural ventilation. Slovak J. Anim. Sci., 42: 167-173.

Bun C., Wat an abe Y., U e no y a ma Y., In ou e N., I e d a N., M a t s u d a F., Ts u k a mura H., Kuwahara M., Maeda K.I., Ohkura S., Pheng V. (2018). Evaluation of heat stress response in crossbred dairy cows under tropical climate by analysis of heart rate variability. J. Vet. Med. Sci., 80: 181-185.

Card ot V., L e R o ux Y., J u r j an z S. (2008). Drinking behavior of lactating dairy cows and prediction of their water intake. J. Dairy Sci., 91: 2257-2264. 
Cha i y abutr N., Chan pongs ang S., S u a d s ong S. (2008). Effects of evaporative cooling on the regulation of body water and milk production in crossbred Holstein cattle in a tropical environment. Int. J. Biometerol., 52: 575-585.

C o 11 i e r R.J., D a h 1 G.E., Van B a a le M.J. (2006). Major advances associated with environmental effects on dairy cattle. J. Dairy Sci., 89: 1244-1253.

Colli er R.J., Gebremedhin K., M a c k o A.R., R o y K.S. (2012). Genes involved in the thermal tolerance of livestock. In: Environmental stress and amelioration in livestock production, Sejian V., Naqvi S.M.K., Ezeji T., Lakritz J., Lal R. (eds). Springer-Verlag (publisher), Berlin Heidelberg, Germany, pp. 379-410.

Da lc in V.C., F is cher V., Daltro D.D., A 1 fonzo E.P., S t u m p f M.T., Kolling G.J., Silva M.V., M c Manus C. (2016). Physiological parameters for thermal stress in dairy cattle. R. Bras. Zootec., 45: 458-465.

D a Silva R.G., Guilh er m in o M.M., Mor a is D.A.E.F. (2010). Thermal radiation absorbed by dairy cows in pasture. Int. J. Biometeorol., 54: 5-11.

Davis S., Mader T. (2003). Adjustments for wind speed and solar radiation to the temperaturehumidity index. Nebr. Beef. Cattle Rep., 224: 48-51.

D e a t o n C.H.M., M a r 1 i n D.J. (2003). Exercise-associated oxidative stress. Clin. Tech. Equine Prac., 2: 278-291

D o t a n Y., L i c h t e n b e rg D., P in c h u k I. (2004). Lipid peroxidation cannot be used as a universal criterion of oxidative stress. Prog. Lipid Res., 43: 200-227.

E ig enberg R.A., Brown-Brand 1 T.M., Ni en aber J.A., Hahn G.L. (2005). Dynamic response indicators of heat stress in shaded and non-shaded feedlot cattle, Part 2: Predictive Relationships. Biosyst. Eng., 91: 111-118.

Gaw orski M., Rocha A.G.F. (2016). Effect of management practices on time spent by cows in waiting area before milking. In: Engineering for Rural Development, Malinovska L., Osadcuks V. (eds). Latvia Univ. Agriculture, Latvia, pp. 1300-1304.

Godyń D., Herbut E., Wa lczak J. (2013). Infrared thermography as a method for evaluating the welfare of animals subjected to invasive procedures - a review. Ann. Anim. Sci., 13: 423-434.

González Pereyra A.V., Maldonado May V., Catracchia C.G., Herrero M.A., F lores M.C., Mazzin i M. (2010). Influence of water temperature and heat stress on drinking water intake in dairy cows. Chil. J. Agric. Res., 70: 328-336.

Ham mami H., B ormann J., M'Hamdi N., Montaldo H.H., Gengler N. (2013). Evaluation of heat stress effects on production traits and somatic cell score of Holsteins in a temperate environment. J. Dairy Sci., 96: 1844-1855.

H a r m on R.J., L u M., Tr a m m e l D.S., S m i th B.A. (1997). Influence of heat stress and calving on antioxidant activity in bovine blood. J. Dairy Sci., 80: 264.

Hempel S., König M., Menz C., Janke D., Amon B., Banhazi T.M., Estellés F., A m o n T. (2018). Uncertainty in the measurement of indoor temperature and humidity in naturally ventilated dairy buildings as influenced by measurement technique and data variability. Biosyst. Eng., 166: 58-75.

H e r b u t P. (2013). Temperature, humidity and air movement variations inside a free stall barn during heavy frost. Ann. Anim. Sci., 3: 587-596.

He r b u t P., A n g re c k a S., N a w a 1 a n y G. (2013). Influence of wind on air movement in a free stall barn during the summer period. Ann. Anim. Sci., 13: 109-119.

Herbut P., Angrecka S. Godyń D. (2018 a). Effect of the duration of high air temperature on cow's milking performance in moderate climate conditions. Ann. Anim. Sci., 18: 195-207.

Herbut P., A ngrecka S., Wa lc z a k J. (2018 b). Environmental parameters to assessing of heat stress in dairy cattle - a review. Int. J. Biometerol., 62: 2089-2097.

H i 11 D.L., Wa 11 E. (2015). Dairy cattle in a temperate climate: the effects of weather on milk yield and composition depend on management. Animal, 9: 138-149.

Hoffmann G., Schmidt M., A mmon C., Rose-Meierhöfer S., Burfeind O., Heuwi e s e r W., B e rg W. (2013). Monitoring the body temperature of cows and calves using video recordings from an infrared thermography camera. Vet. Res. Commun., 37: 91-99.

Hu e N.T., Tran H.T., Phan T., N a k a mura J., I wat a T., Harano K., Is hib a shi Y., Yuas a T., I w a y a-I n o u e M. (2013). Hsp90 and reactive oxygen species regulate thermotolerance 
of rice seedlings via induction of heat shock factor A2 (OsHSFA2) and galactinol synthase 1 (OsGolS1). Agric. Sci., 4: 154-164.

J ohn s on J.M., Prop pe D.W. (1996). Cardiovascular adjustments to heat stress. In: Handbook of physiology: Environmental physiology, Fregly M.J., Blatteis C.M. (eds). Oxford University Press, New York, USA, pp. 215-243.

Johnson J., Abuajami eh M., Sanz M.V., Seibert J., Kvidera S., Ross J., Selsby J., Gabler N., Xin H., Lucy C.M., S a franski T.J., Rhoads R., B a umgard L. (2013). Heat stress alters energy metabolism during pre- and postnatal development. Proc. Mexicali Heat Stress Symposium. Doi: 10.13140/2.1.3792.0961.

K a dzere C.T., Murphy M.R., S i l a n i k ove N., M a ltz E. (2002). Heat stress in lactating dairy cows: a review. Livest. Prod. Sci., 77: 59-91.

K ová c s L., Ké zér F.L., R uff F., Jurk ovi ch V., S ze n c i O. (2018). Assessment of heat stress in 7-week old dairy calves with non-invasive physiological parameters in different thermal environments. Plos One, 13: e0200622.

L a m bertz C., S a n ker C., Ga u ly M. (2014). Climatic effects on milk production traits and somatic cell score in lactating Holstein-Friesian cows in different housing systems. J. Dairy. Sci., 97: 319-329.

Lavon Y., Leitner G., Moallem U., Klipper E., Voet H., Jacoby S., Glick G., Meid a n R., Wolfen s on D. (2011). Immediate and carryover effects of Gram-negative and Gram-positive toxin-induced mastitis on follicular function in dairy cows. Theriogenology, 76: 942-953.

L e e D.H.R. (1965). Climatic stress indices for domestic animals. Int. J. Biometeorol., 9: 29-35.

L e e s A.M., L e e s J.C., L i s 1 e A.T., S u 11 i v a n M.L., G a u g h a n J.B. (2018). Effect of heat stress on rumen temperature of three breeds of cattle. Int. J. Biometeorol., 62: 207-215.

L e m e r l e C., G o d d a r d M.E. (1986). Assessment of heat stress in dairy cattle in Papua New Guinea. Trop. Anim. Health Prod., 18: 232-242.

Lendelova J., B ot to L., Pogran S., Reich stadterova T. (2012). Effect of different cooling system on lying time of dairy cows in cubicles with separated manure solids bedding. J. Cent. Europ. Agric., 13: 717-728.

Mauger G., B a uman Y., N ennich T., S a lathé E. (2015). Impacts of climate change on milk production in the United States. Prof. Geogr., 67: 121-131.

M in L., Ch en g J., S h i B., Yang H., Z h en g N., W ang J. (2015). Effects of heat stress on serum insulin, adipokines, AMP-activated protein kinase, and heat shock signal molecules in dairy cows. J. Zhejiang Univ. Sci., B, 16: 541-548.

M or i m o t o R.I., T is s i e r e s A., G e or g o p ou 1 o s C. (1990). Stress proteins in biology and medicine. Cold Spring Harbor Laboratory Press, Cold Spring Harbor, N.Y., USA, pp. 323-359.

National Research Council (1981). Subcommittee on Environmental Stress. Effect of Environment on Nutrient Requirements of Domestic Animals. Washington (DC), USA, National Academies Press, ISBN-10: 0-309-03181-8, $168 \mathrm{pp}$.

Noordhuizen J., B onnefoy J.M. (2015). Heat stress in dairy cattle: major effects and practical management measures for prevention and control. SOJ Vet. Sci., 1: 1-7. Doi: http://dx.doi. org/10.15226/2381-2907/1/1/00103.

Padilla L., Matsu i T., Kam i ya Y., Kamiya M., Tanaka M., Yano H. (2006). Heat stress decreases plasma vitamin C concentration in lactating cows. Livest Sci., 101: 300-304.

P e arce S.C., Mani V., B odd i cker R.L., Rho ads R.P., We ber T.E., Ros s J.W., B a u mg a r d L.H., G a b le r N.K. (2013). Heat stress reduces intestinal barrier integrity and favors intestinal glucose transport in growing pigs. Plos One, 8: e70215.

Pilatti J., Vieira F. (2017). Environment, behavior and welfare aspects of dairy cows reared in compost bedded pack barns system. J. Anim. Behav. Biometeorol., 5: 97-105.

P i l a t t i J., Vieira F., R a n krape F., Vis mara E. (2018). Diurnal behaviors and herd characteristics of dairy cows housed in a compost-bedded pack barn system under hot and humid conditions. Animal, 13: 399-406.

Pragna P., Archana P.R., A leena J., Sejian V., Krishnan G., B agath M., Manimaran A., B e en a V., Kurien E.K., Varma G., B hat t a R. (2017). Heat stress and dairy cow: impact on both milk yield and composition. Int. J. Dairy Sci., 12: 1-11. 
Purwanto B.P., A bo Y., S a ka moto R., Furum o to F., Ya ma mo to S. (1990). Diurnal patterns of heat production and heart rate under thermoneutral conditions in Holstein Friesian cows differing in milk production. J. Agric. Sci., 114: 139-142.

Rhoads M.L., Rhoads R.P., Van B a le J., Collier R.J., S anders S.R., Weber W.J., Cr o o k er B.A., B a u m g a d L.H. (2009). Effects of heat stress and plane of nutrition on lactating Holstein cows: I. Production, metabolism, and aspects of circulating somatotropin. J. Dairy Sci., 92: 1986-1997.

R h o a d s R.P., B a u m g ard L., S a u g e e J.K. (2013). Metabolic priorities during heat stress with an emphasis on skeletal muscle. J. Anim. Sci., 91: 2492-2503.

R i s c o C.A., B e n z a que n M. (2011). Monitoring health and looking for sick cows. In: Dairy production medicine, Risco C.A., Melendez P. (eds). Blackwell Publishing Ltd., Oxford, Great Britain, pp. 27-32.

S chutz K.E., C ox N.R., M a t thew s L.R. (2008). How important is shade to dairy cattle? Choice between shade or lying following different levels of lying deprivation. Appl. Anim. Behav. Sci., 114: 307-318.

S chutz K.E, R o ger s A.R., C ox N.R., Tu c ker C.B. (2009). Dairy cows prefer shade that offers greater protection against solar radiation in summer: Shade use, behaviour, and body temperature. Appl. Anim. Behav. Sci., 116: 28-34.

S lim en B.I., Taha N., A b d e lj elil G., Man ef A. (2016). Heat stress effects on livestock: molecular, cellular and metabolic aspects, a review. J. Anim. Physiol. Anim. Nutr., 100: 401-412.

S mith D.L., S m ith T., Ru d e B.J., Ward S.H. (2013). Short communication: Comparison of the effects of heat stress on milk and component yields and somatic cell score in Holstein and Jersey cows. J. Dairy Sci., 96: 3028-3033.

St-Pi erre N.R., C obanov B., S chnitkey G. (2003). Economic losses from heat stress by US livestock industries. J. Dairy. Sci., 86 (E. Suppl.): 52-77.

S tevens D.C. (1981). A model of respiratory vapor loss in Holstein dairy cattle. Trans ASAE, 24: $151-153$.

T a y l o r N.A., T i p t o n M.J., K e n n y G.P. (2014). Considerations for the measurement of core, skin and mean body temperatures. J. Therm. Biol., 46: 72-101.

Tu c k e r C.B., R o ger s A.R., S c h u t z K.E. (2008). Effect of solar radiation on dairy cattle behaviour, use of shade and body temperature in a pasture-based system. App. Anim. Behav. Sci., 109: 141-154.

Turk R., P odpečan O., Mrkun J., Fle gar-M eštrić Z., P e rkov S., Zri mš ek P. (2015). The effect of seasonal thermal stress on lipid mobilisation, antioxidant status and reproductive performance in dairy cows. Reprod. Domest. Anim., 50: 595-603.

Unruh E.M., Theurer M.E., White B.J., Larson R.L., Drouillard J.S., Schrag N. (2017). Evaluation of infrared thermography as a diagnostic tool to predict heat stress events in feedlot cattle. Am. J. Vet. Res., 78: 771-777.

Van Laer E., Palmyre C., Moons H., Sonck B., André F., Tuyttens M. (2014). Importance of outdoor shelter for cattle in temperate climates. Livest. Sci., 159: 87-101.

Wang X., B j e rg B.S., Ch o i Ch., Z ong Ch., Z h ang G. (2018). A review and quantitative assessment of cattle-related thermal indices. J. Therm. Biol., 77: 24-37.

Werner J., M ekjavi c I.B., Ta y lor N.A.S. (2008). Concepts in physiological regulation: a thermoregulatory perspective. In: Physiological bases of human performance during work and exercise, Taylor N.A.S., Groeller H. (eds). Churchill Livingstone, London, United Kingdom, pp. 325-340.

We s t J.W. (2003). Effects of heat-stress on production in dairy cattle. J. Dairy. Sci., 86: 2131-2144.

We s t J.W., M ulli n ix B.G., B e r n a rd J.K. (2003). Effects of hot, humid weather on milk temperature, dry matter intake and milk yield of lactating dairy cows. J. Dairy Sci., 86: 232-242.

We s tw o o d C.T., L e a n I.J., G a rvin J.K. (2002). Factors influencing fertility of Holstein dairy cows: a multivariate description. J. Dairy Sci., 85: 3225-3237.

Whe elo ck J.B., Rhoads R.P., Vanba le M.J., S anders S.R., B a umgard L.H. (2010). Effects of heat stress on energetic metabolism in lactating Holstein cows. J. Dairy Sci., 93: 644-655.

W i 1 s o n T.E., C r a n d a 11 C.G. (2011). Effect of thermal stress on cardiac function. Exerc. Sport Sci. Rev., 39: 12-17. 
Ya z g a n K., C e d d e n F., D a ş t a n be k C. (2013). Effects of air temperature and humidity on average daily gain in feedlot cattle of different genotypes. Arch. Tierz., 56: 28-41.

Received: 31 VII 2018

Accepted: 7 II 2019 